\title{
A TIBIAL GLAND SCENT-TRAIL AND TRAIL-LAYING BEHAVIOR IN THE ANT \\ CREMATOGASTER ASHMEADI MAYR.
}

\author{
By R. H. LeUthold*
}

The Biological Laboratories, Harvard University, Cambridge, Mass.

\section{INTRODUCTION}

Wasmann ( 1899) speculated that ants might lay odor trails by using their feet. But with the exception of a challenge by Brun (1914), the footprint hypothesis was laid dormant. In all ant species thus far analysed, trail-substances originate from the gaster of the ant, whether the instrument is the sting, as in the Myrmicinae, the anus, as in the stingless Ponerinae, Dorylinae and Formicinae, or the posterior border of the sixth abdominal sternite as in Dolichoderinae (Wilson 1963, Gabba 1967).

The myrmicine ant, Crematogaster ashmeadi, obviously builds up scent trails for communication. However, the gasters of workers are never seen to touch the substrate, not even when a new trail is being established. The workers often erect the abdomen upward and, especially when excited, they even bend it forward superimposed to the thorax so that they take on the superficial appearance of a little spider rather than an ant. Their sting is often protruded, but it never touches the ground.

Goetsch ( 1934) observed the peculiarity of the trail-laying of the Mediterranean species Crematogaster scutellaris. He also noticed that they never touch the substrate with their abdomen. He describes the behavior of trail-laying workers as the following: "The ant performs a kind of dancing step folding its hindlegs". He suspected the pheromone source to be somewhere in the gaster and claimed that the trail substance is possibly released as a vapor, the hindlegs functioning to support the gaster at a fixed height above the ground. The described behavior is compatible with my observations in $C$. ashmeadi, but our interpretations differ greatly. The dancing step of the hindlegs, in fact, is a description of trail-laying by footprints. It will now be shown that a physiologically functional system of trail-laying has evolved in $C$. ashmeadi that involves the hindlegs, a system which early naturalists were thinking about without having seen it.

While this article was in preparation and after my own analysis had been completed, there appeared a report by Fletcher and Brand

\footnotetext{
*Present address: Zoologisches Institut der Universität Bern, Switzerland.
} 
( I968) describing the trail-laying behavior of Crematogaster peringueyi. This work has independently established the existence of tarsal trail-laying in Crematogaster. In the present article, I report the same form of trail-laying in a second species of Crematogaster and identify for the first time the location of the gland reservoir and discuss some of the physical and chemical properties of the pheromone.

\section{MATERIALS AND METHODS}

C. ashmeadi is an arboreal ant, dwelling in dead hollow branches and in all kind of cavities in dead wood. Its range is the coastline from Virginia to Florida and the Eastern Gulf States (Creighton 1950). In my field studies on the Florida Keys the existence of efficient scent trails in $C$. ashmeadi has been verified by means of traditional experiments.

Our laboratory colonies, collected from red mangrove trees (Rhizophora mangle), were established in horizontally piled pieces of hollow mangrove branches, on wooden frames of $20 \times 25 \mathrm{~cm}$, kept in plastic trays of $30 \times 45 \times 17 \mathrm{~cm}$ in size with the inside walls coated with talcum powder to prevent escape. A horizontal cylindrical wooden bridge, $3 \mathrm{~cm}$ in diameter and $50 \mathrm{~cm}$ in length, connected the nest area with the feeding station where the ants were offered water, honey and shrimp. The colonies were kept at regular room temperature. To begin trail-laying experiments a colony was first starved for 5 days, then a movable side bridge of $24 \mathrm{~cm}$ in length was added to the old pathway between the nest and feeding station. By maneuvering this side connection we were able to offer a scouting ant a new honey source and control the passages of newcomers. Movements were analysed by slow motion cinematography ( $16 \mathrm{~mm}$ film, 64 frames per second).

Localization of an active source of the trail in the ant body was accomplished by extracting fractionated body parts in petroleum ether. Collected batches of identical body parts of 20 ants were crushed

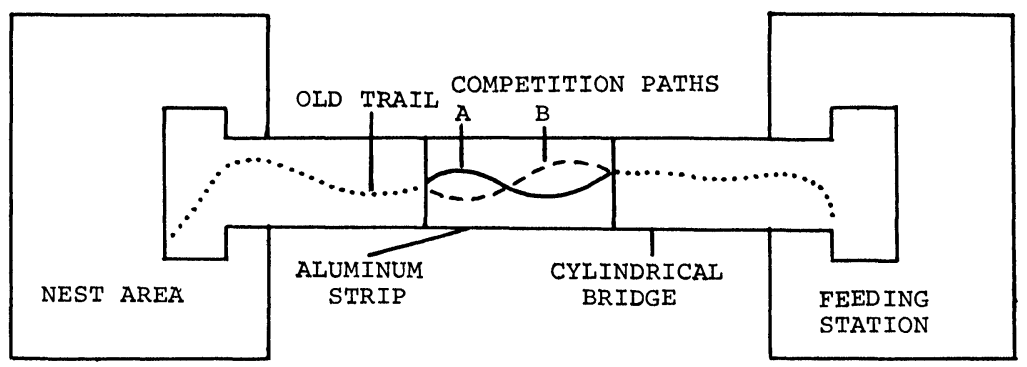

Fig. 1. - Schematic of bridge structure used in trail assays. 
together with IOO $\mu \mathrm{l}$ of petroleum ether as a standard solution. All bioassays were executed on the main bridge of a laboratory nest during times that the traffic on the trail was moderate. By coating the times that the traffic on the trail was moderate. By coating the cylindrical bridge with a $10 \mathrm{~cm}$ wide strip of aluminum foil the old trail was interrupted. Two rival artificial trails crossing each other in the form of an " 8 " were laid over the foil and offered to the ants (fig. I). Both trails had ben drawn out of $2.4 \mu \mathrm{l}$ of a standard extract and were offered the ants after evaporation of the solvent. If in such a case neither trail is active some ants show no particular preference to one over the other and they may well follow either trail just as they do on any kind of line leading in the general right direction. With rival trails, however, each ant must decide twice between two different lines to follow, once at the start of the trails and once again at their crossing point. If only one of the lines contains a trace of the real trail pheromone it is closely followed by almost $100 \%$ of all trail-follower ants (a basic rate of nonfollowers of I to $12 \%$, depending on the degree of starvation, is normally observed also on natural trails). In cases in which both trails contained some active component, one of them was claimed to be dominant only when it was followed by at least $75 \%$ of all trail followers in three successive assays.

To establish the morphological site of the origin of the trail pheromone the following methods were used: dissection of the hindlegs under water, microscopy of unpigmented legs of old pupae, and cross-sectioning of adult legs.

The histological techniques employed are:

I. Fixation of whole legs (with incisions in femur, tibia and metatarsus) in $3 \%$ glutaraldehyde in a phosphate buffer of $\mathrm{pH}$ 7.3-7.4.

2. Embedding into Maraglas (an Epoxy embedding media) (after Erlandson I964).

3. Staining with methylene blue for light microscopy.

The quality of the sections was high, but the rate of loss was too great to obtain complete series.

\section{TRAIL-LAYING BEHAVIOR}

Individuals of $C$. ashmeadi returning from a newly discovered food source (see methods) shuffle their hindlegs and never touch the soil with their abdomen as other ants do. The method of trail-laying in $C$. ashmeadi results in a more or less deliberate setting of footprints. A very active trail-laying ant moves slowly and looks almost 

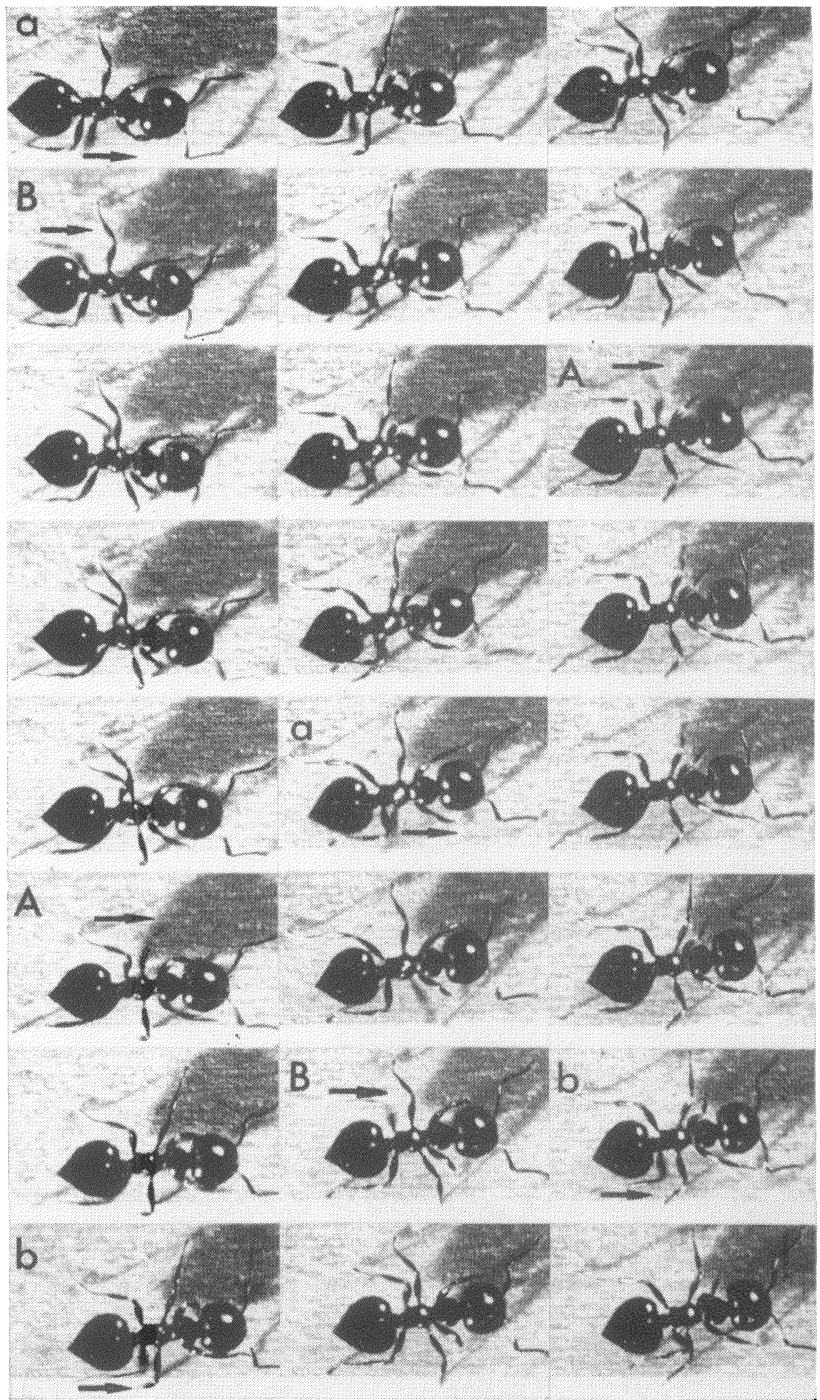

Regular walking of a newcomer ant toward the food (slow motion, 64 frames per second) (compare fig. 2). 


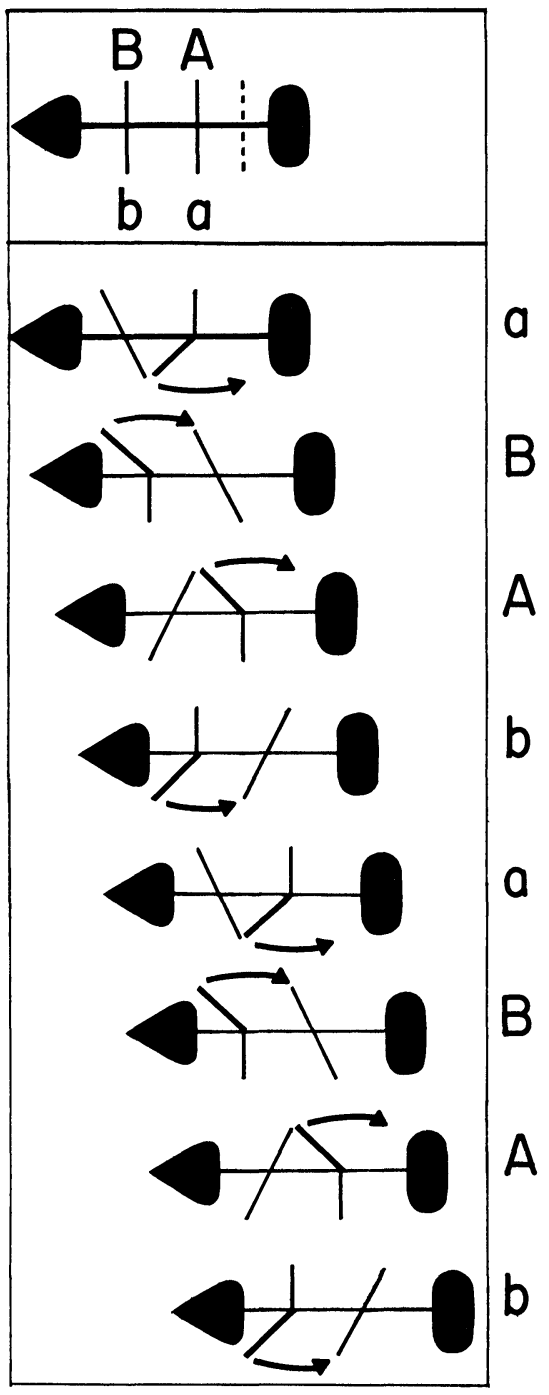

Fig. 2 - Regular walking (schematic representation of plate 17): Comparison of leg participation for locomotion, demonstrated between midlegs and hindlegs.

$\mathrm{Aa}=$ midlegs, $\mathrm{Bb}=$ hindlegs

Walking pattern: aBAbaBAb

B

A

b

a

$B$

A

b 
as though it is "marking time" with its hindlegs, which are pulled in beneath its abdomen in a "knock-kneed" posture (plate I8). In a dorsal view, consequently, only the oscillating knee can be seen clearly, and it is often rapidly stroked forward. The movement of the hindlegs, in this case, is performed independently from the other legs and without participation in locomotion, whereas in the ants' regular, wide-treaded gait a definite pattern of alternation in participation of all legs is maintained (plates $\mathrm{I} 7$ and $\mathrm{I} 8$, figures 2, 3 and $4 \mathrm{~A})$.

The analysis of slow-motion pictures from a lateral view proves that the hindfeet often dab the substrate without the whole leg being obviously stroked (fig. 4 A frames 4 and 8, fig. 4 B frames 7 to II). The whole distal part of the tarsus up to the metatarsus joint is occasionally bent down to the substrate, while the heel moves up and down, and the claw is sometimes raised (fig. $4 \mathrm{~A} \mathrm{~B}$ ). In addition a slight dragging of the hindfoot was occasionally observed (fig. $4 \mathrm{~A}$ frame 2, fig. $4 \mathrm{~B}$ frame 12 ). The trail-laying behavior of a forager on her way back toward the nest is not always clear and definite. A continuous change from the most intensive form of shuffling to an almost regular walking step can be observed. Fig. $4 \mathrm{C}$ shows an average trail-setting. Also here an autonomous foot-dabbing against the substrate occurs, but the feet are kept farther apart.

In order to investigate the efficiency of a single trail-layer, an ant from a starved colony was allowed to find food at the end of the sideturn bridge. After feeding such an explorer performs a very strong trail-laying on her return. Trail-laying often becomes weaker toward the end of the long uniform part of the bridge but increases again when passing the obstacle of the connection from the new bridge to the old one. From the point onto the old trail a very brief but strong episode of trail-laying is typical, usually being maintained for only a few centimeters on the old runway. Then trail-laying decreases; the recruiter runs back and forth on the old trail exciting other nestmates, and finally she returns to the food or at least close to it. Trail-setting is performed even on the way toward the food, but usually more vigorously on the return trip. If the bridge is connected only for the passages of the one recruiter ant but not for other newcomers, this back-and-forth game can be repeated as many times as the observer wishes.

It is obvious that, in most cases, the trail from one single run is not efficient enough to lead newcomers reliably to the goal, except on very short feeding bridges. The explorer ant itself, however, is usually able to follow its own first trail, taking cues where trail-laying was 
most efficient and probably relying to some extent on visual orientation. With each run the trail is improved, so that after three return passages on the average ( 6 experiments in which $4,3,3,3,2$ and I return passages were needed) at standard conditions (see Methods) it was efficient enough to guide newcomers accurately to the goal (fig. 5). All new ants from the food source contribute in trail-laying. With an increasing number of ants, curved paths in the trail become gradually flattened out into straight lines. This is an expected result since the ants have a tendency to follow each other as well as the trail, and they start cutting the curves as soon as they become crowded on the trail. The fact that a new shape of trail is established regardless of the original one means that, in this phase, the concentration of the trail is still increasing. After $1 / 2$ to $\mathrm{I}$ hour no further typical trail-laying behavior can be seen, even though there is still a high foraging activity. Whenever a well established trail is covered by a band of aluminum foil, the ants first hesitate in crossing over, but very soon they walk over the strip, scattered but holding their main direction. Within a few minutes a new trail on the obstacle is established by the crowd of crossing ants. However, the typical active trail-setting behavior with their hindlegs cannot be observed in this case. Hence we have to conclude that footprints of lower efficiency are set as well during regular (or at least not obviously modified) walking. This "passive" trail-laying, when hundreds of ants wall over the same place, is efficient enough to maintain, replace or change successively an old trail, whereas the "active" trail-laying enables a single ant to establish an efficient new trail, a communicative device used primarily during the recruitment phase to a new food source.

LOCALIZATION OF THE PHEROMONE SOURCE

By selective bioassaying the petroleum ether standard extracts of different body parts (see methods) the hind tibiae of $C$. ashmeadi turned out to contain the trail substance. Dissections of the hindleg showed the tendon of the claw to be swollen into a spindle-shaped reservoir located in the tibia (pl. 19). As is common in insects the claw tendon originates in the femur, with muscle insertions in the femur and tibia, and runs through the whole leg down to the terminal joint. The actual reservoir is a specially adapted structure seemingly adapted to a role in trail-laying. It contains an oil-like liquid. One single droplet of approximately $0.03 \mathrm{~mm}$ in diameter transferred with a pipette into $20 \mu$ ! of petroleum ether yields $100 \%$ positive trailfollowing using $2.4 \mu \mathrm{l}$ for a $\mathrm{I} 2 \mathrm{~cm}$ long trail, compared with a control made up out of haemolymph and muscle tissue from the same 


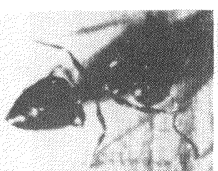

B
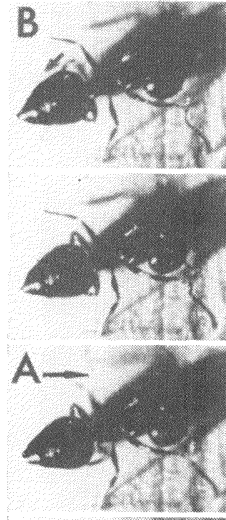

b
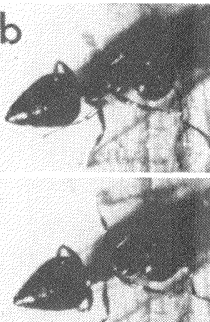

(n)

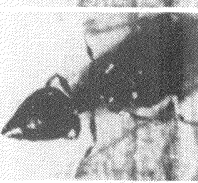

B

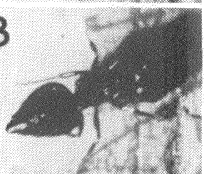

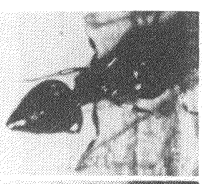
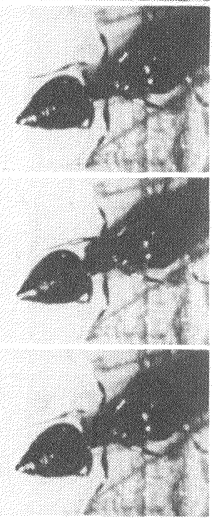

b
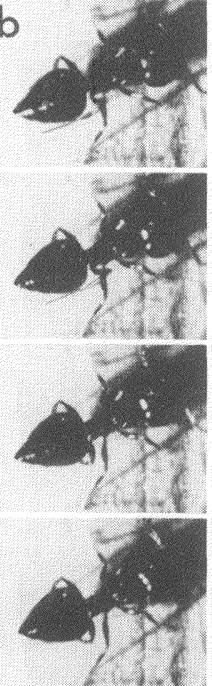

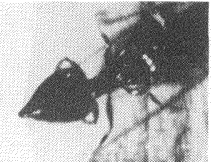

B
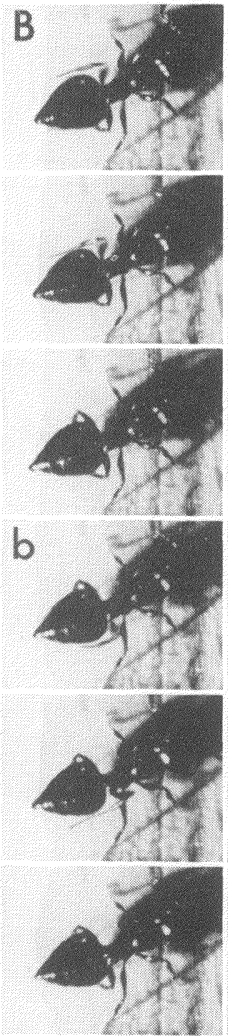

A

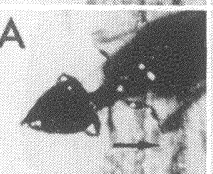

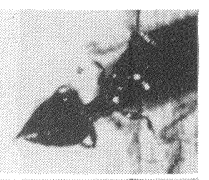

B
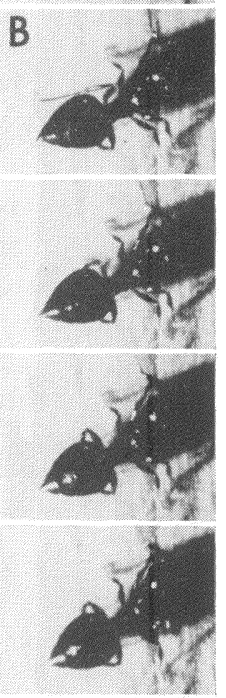

b
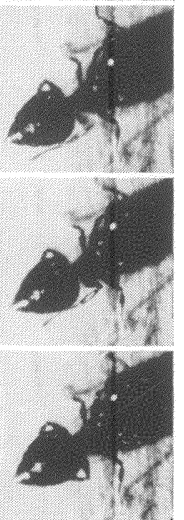

Trail-laying of an explorer ant returning from the food (slow motion, 64 frames per second) (compare fig. 3 ). 


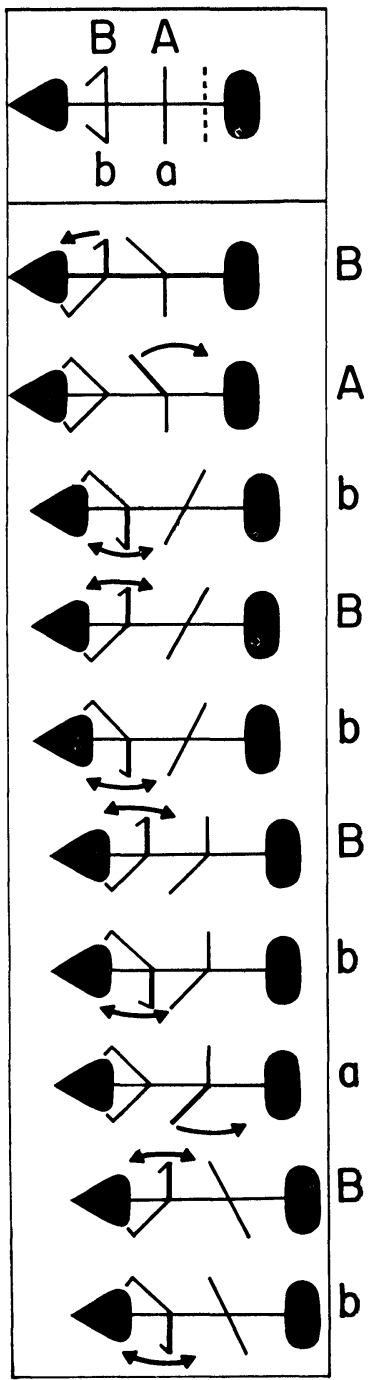

Fig. 3-Trail-laying (schematic representation of plate 18): Hindlegs not in correlation with midlegs and not participating in locomotion (forelegs are correlated with midlegs). The strokes of the hindlegs are described as "marking time" movements (see text).

$\mathrm{Aa}=$ midlegs, $\mathrm{Bb}=$ hindlegs

Moving pattern: $\mathrm{BAbBbBbaBb}$

A

b

$B$

b

$B$ b 


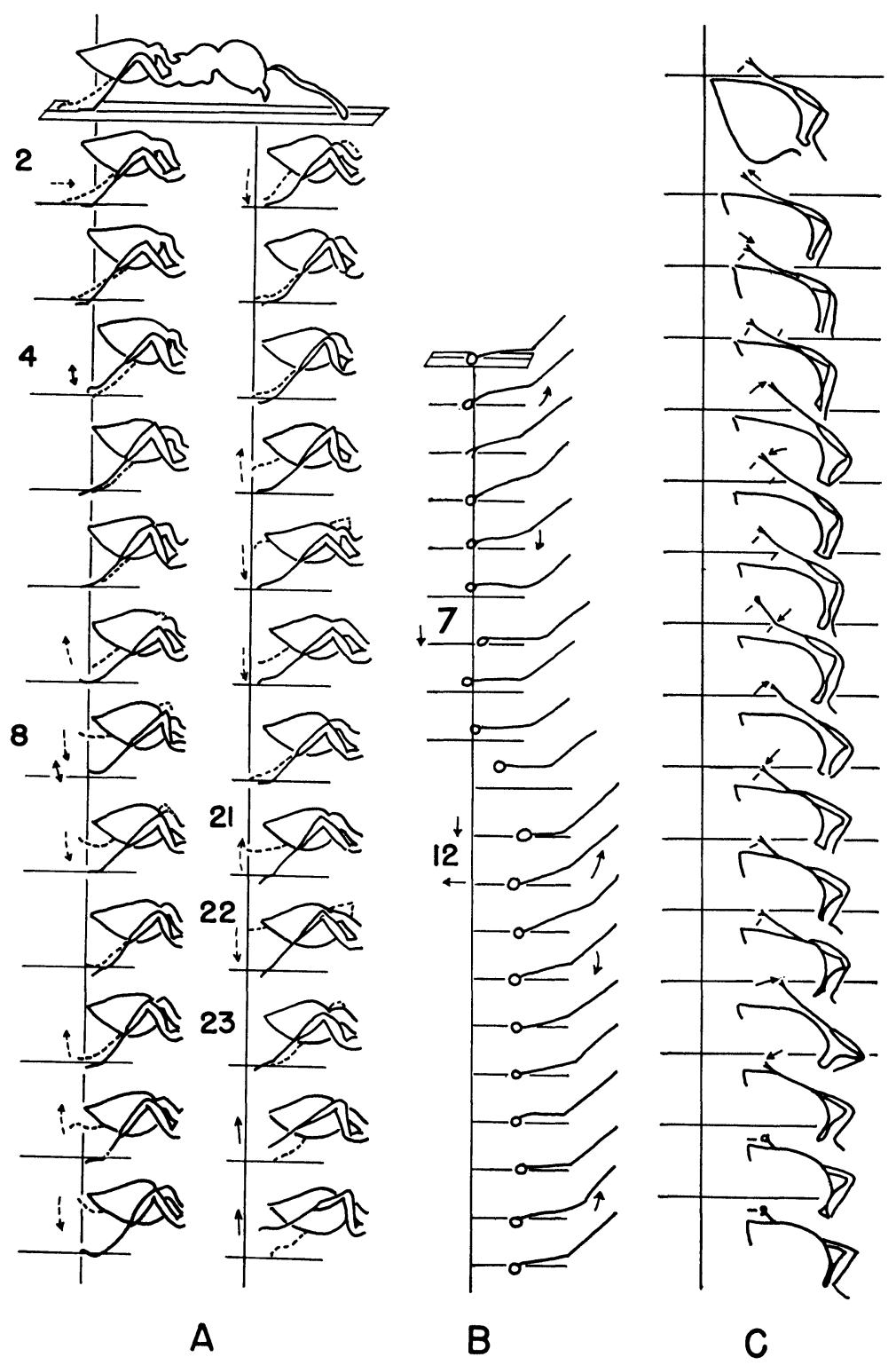


leg. This bioassay, repeated positively five times, proved that this oil-like substance is, or at least contains the trail pheromone.

As evidence that the spindle reservoir is part of the tendon, it can be shown that pulling the reservoir slightly with a pair of forceps moves the pretarsus. The whole tendon organ can also easily be pulled out from the leg together with the attached muscles and with an oblong mass of tissue partially coating the spindle (pl. I9 B). The spindle itself is rather stiff and the fibers are relatively tough. The distal fiber of the tendon however always tears off somewhere in the mesotarsus. The content of the spindle is easily stained blue with Sudan black (Romeis 1948) by dipping the whole organ into a $50 \%$ alcoholic stain solution (pl. I9 C D). This procedure shows that the spindle is filled only with lipophile substance. Sometimes an empty space, illustrated in pl. 19 C, can be seen which might be an artifact of stretching. On a microslide, a slight and careful pressure on the coverglass drives the blue liquid up to, but not beyond a place which corresponds approximately to the knee between femur and tibia (pl. I9 D). Like a folded fire hose, expanded by the pressure of the water, this upper part is opened by internal pressure. The lower extension of the spindle, however, is stiff and hollow. Tiny blue droplets were successfully driven out at the place of the distal end of the metatarsus. However, the spindle sometimes collapsed before this emission occurred. Also, such droplets could be driven out by pressure on the tibia after opening up the tendon at the lower end of the metatarsus but not beyond this place (pl. I9 A).

The natural opening to disperse the trail pheromone is believed to be in the pretarsus, but this location has not been conclusively established yet. From the partially complete histological series of cross sections there is no evidence for the tendon lumen to be discontinuous (pl. I9 E) and no side exit has been found. As far as it is conclusive from the cross sections and from total micro-preparations, it may be that the tendon lumen opens into the ventral area on the end of the fifth tarsomere (pretarsus). Further histological investigation is in progress. The analysis of the hindleg movement in trail-laying individuals supports the idea that the pheromone is spread from the pretarsus (fig. $4 \mathrm{~A} \mathrm{~B}$ ). On the other hand, it does

Fig. 4. (opposite page) - Slow motion sequences (64 frames per second) of trail-laying ants.
A. Hindlegs from lateral view
B. Foot movements from lateral view
C. Moderately active trail-laying from dorsal view (short black lines indicate positions on the legs in contact with surface). 


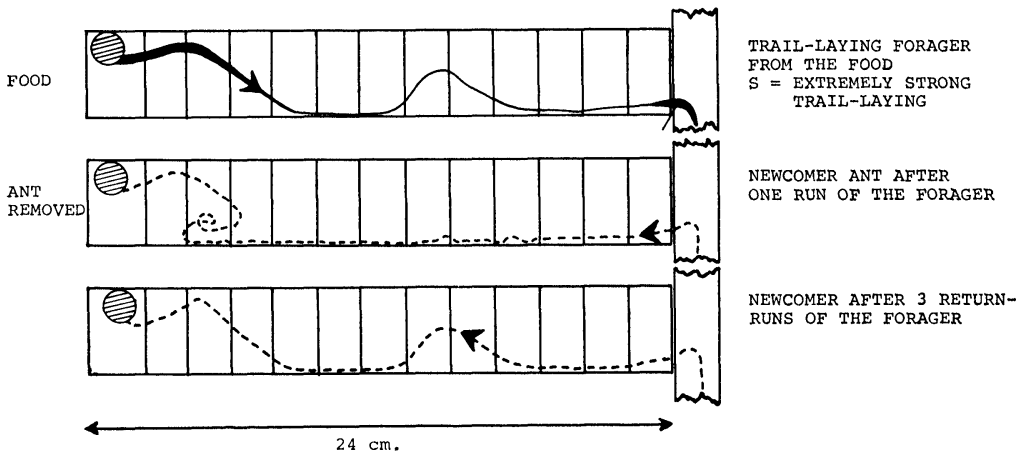

Fig. 5. - Experimental result to exhibit the efficiency of trail establishment on a graduated side bridge. Observations were transcribed from dictaphone.

not exclude the possibility that the pheromone could be dispersed from some other place in the lower tarsus, since this is occasionally bent to the substrate during trail-laying (see behavior).

Where exactly is the trail pheromone produced? A final answer to this question can be given only after more extensive histological work. It is most probable that the tissue coating the spindle reservoir is the pheromone gland ( $\mathrm{pl}$. I9 B gl), since no other likely tissue has been found. A chain of large granulated cells of unknown function, going out from the distal part of the tibia (fig. A y), does not seem to have any connection with the spindle.

\section{Explanation of Plate 19}

Morphological aspects of the hindleg

A. Pretarsal tendon in situ.

ch = chorodotonal organ

$\mathrm{y}=$ chain of cells of unknown function

$A_{1}$. Tendon, opened up at the end of the metatarsus. A droplet of trail substance is released by pressure on the tibia.

B. Tendon pulled out with muscle attachments $\mathrm{gl}=$ apparent pheromone gland

$\mathrm{m}=$ muscle tissue

$\mathrm{sp}=$ spindle-shaped pheromone reservoir

C. Tendon-spindle pulled out and stained with Sudan-black (empty space, probably from stretching)

D. Stained tendon-spindle after slight lateral pressure

E. Cross sections showing the tendon-organ (numbers correspond to A)

te $=$ tendon

tr $=$ trachea 


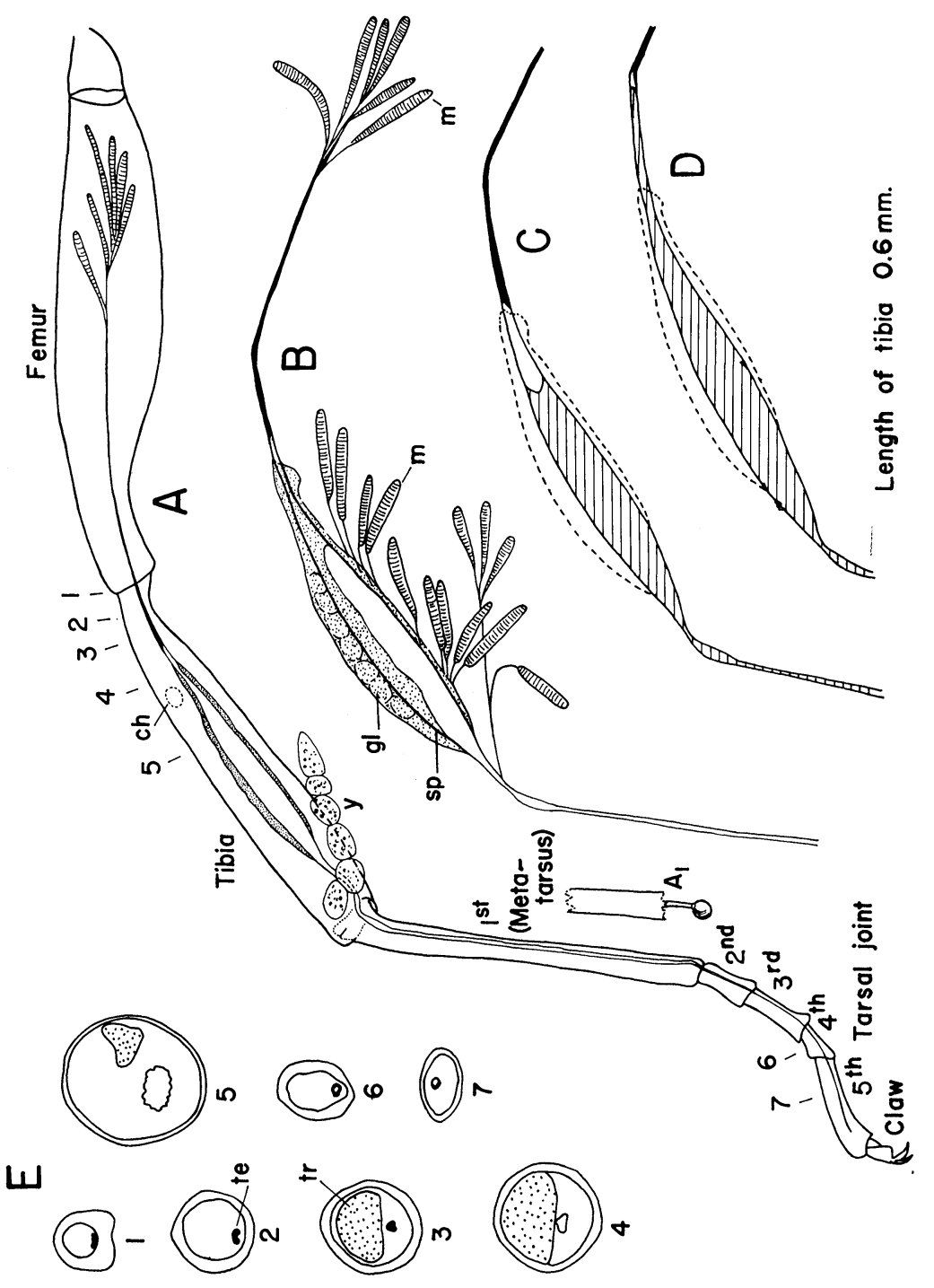




\section{QUALITATIVE AND QUANTITATIVE ASPECTS}

The odor trail in $C$. ashmeadi has been considered as an "exploratory" trail rather than a "recruitment" trail, following the definition of Wilson (1963). This means that the trail directs ants from one place to the other without any exciting component of recruitment (The recruitment behavior in $C$. ashmeadi will be reported in a separate paper). The relatively long lasting time of a trail makes it also serve as a persistent "trunk route" (Wilson 1963). Field and laboratory experiments confirm that well established natural trails on paper last approximately $24-48$ hours at $28^{\circ} \mathrm{C}$ with constantly decreasing efficiency. However, artificial trails prepared from petroleum ether extracts and exhibiting the initial efficiency of about a natural trail (rival bioassay), are shorter lasting than the natural ones, and their efficiency depends on the substrate material. They remain active longer on aluminum foil than on paper, in accordance with the lower threshold concentration needed to activate trail following on foil. For that reason aluminum foil is found to be the most suitable substrate for bioassay. The range of fading times for trails with the approximate efficiency of natural ones is listed below:

Natural trail on paper, wood or aluminum foil: $24-48$ hours

Artificial trail from petroleum ether on aluminum foil: 8-10 hours

Artificial trail from petroleum ether on paper: 2-3 hours Microscopic examination of artificial and natural trails provides evidence that the droplets of trail substance are smaller and more finely dispersed in artificial trails than in natural trails. This fact explains the shorter lasting effect of artificial trails.

Pure tiny spots ( $20 \mu$ in diameter) of trail liquid from the spindle smeared on a microslide glass took $>10$ days to evaporate at $30^{\circ} \mathrm{C}$ (octadecane droplets of the same size evaporate in 5 minutes). Thus the pheromone appears to be a relatively nonvolatile substance. It stains blue with lipoid indicator "Sudan black" (Romeis 1948). A chemical analysis of the substance, also collected from natural trails, is being undertaken.

A few quantitative experiments give us an approximate idea of the trail concentration. How much trail liquid does a leg contain? By optical measurement of the released droplets we obtained (from six legs) an average volume of $0.112 \eta 1$ per leg. (o.137, 0.0824, O.II4, $0.0897,0.120$ and $0.127 \eta 1$ ). From three independent experiments the amount of trail substance needed for a trail of natural efficiency (in rival trail bioassay) is calculated: 


\begin{tabular}{|c|c|c|c|c|}
\hline $\begin{array}{c}\text { No. of legs } \\
\text { containing } \\
0.112 n \mathrm{l} \\
\left(=0.112 \times 10^{-6}\right. \\
\text { ml) each } \\
\end{array}$ & $\begin{array}{c}\text { For natural } \\
\text { efficiency } \\
\text { homogenized } \\
\text { and diluted } \\
\text { to: } \\
\end{array}$ & $\begin{array}{c}\text { Competition } \\
\text { with natural } \\
\text { trail } 1: 1, \\
\text { on substrate: }\end{array}$ & $\begin{array}{c}\text { Solution } \\
\text { per cm on } \\
\text { assay-trail }\end{array}$ & $\begin{array}{l}\text { Caculated trail } \\
\text { substance } \\
\text { per meter }\end{array}$ \\
\hline 1500 & $\begin{array}{c}25000 \mu \mathrm{l} \text { in } \\
\text { petroluem } \\
\text { ether }\end{array}$ & aluminum foil & $3 \mu \mathrm{l} / 12 \mathrm{~cm}$ & $0.168 n \mathrm{I}^{*}$ \\
\hline 20 & $\begin{array}{l}400 \mu \mathrm{l} \text { in } \\
\text { petroluem } \\
\text { ether }\end{array}$ & paper & $2.4 \mu \mathrm{l} / 12 \mathrm{~cm}$ & $0.112 n 1^{*}$ \\
\hline 27 & $\begin{array}{l}640 \mu \mathrm{l} \text { in } \\
\text { water } \\
\text { emulsion }\end{array}$ & paper & $2.4 \mu \mathrm{l} / 12 \mathrm{~cm}$ & $0.094 n 1^{*}$ \\
\hline
\end{tabular}

This result shows that the contents of one single leg yields about I $\mathrm{m}$ of trail standing competition with a naturally established trail. The threshold concentration for trail following in a competition assay on aluminum foil against petroleum ether is even 20 times lower. However, such a trail fades within a few minutes.

\section{SUMMARY}

( I) Crematogaster ashmeadi lay scent trails with their hind feet. The trail pheromone is found to be stored in the hind tibiae in spindle-shaped expansions of the claw tenr.ons. It is driven out through the hollow tendonfiber and released from the lower foot. The source of the pheromone appears to be glandular tissue coating the spindle, but this remains to be verified.

(2) "Active" trail-laying behavior consists of intensive dabbing with the hind feet onto the substrate. It is used primarily during recruitment.

(3) A less efficient, "passive" trail-laying occurs during regular (or at not obviously changed) walking.

(4) The trail substance is a lipophilic material of very low volatility and high behavioral efficiency.

\section{ACKNOWLEDGEMENTS}

I wish to express thanks to Dr. E. O. Wilson for offering me the facilities of his laboratories and for his critical reading of the manuscript. I am also grateful to my wife, Elfie, for her collaboration 
and to Mr. J. M. Reichson and Mr. W. B. Kerfoot for their help and advice rendered during the present study. This work was supported by grants from the Swiss National Science Foundation (Fellowship I967), Stiftung für biologisch-medizinische Stipendien (Fellowship I968) and U.S. National Science Foundation (Grant No. GB 5079, E. O. Wilson, Sponsor).

BRUN, R.

\section{REFERENCES}

1914. Die Raumorientierung der Ameisen, Gustav Fischer, Jena.

Creighton, W. S.

1950. The Ants of North America, Bull. Mus. comp. Zool. Harv., 104. ERLANDSON, R. A.

1964. A new Maraglas D.E.R. 732 embedment for electronic microscopy, J. Cell Biol. 22: 704 .

Fletcher, D. J. C. and Brand, J. M.

1968. Source of the trail pheromone and method of trail laying in the GabBa, A. ant Crematogaster peringueyi, J. Insect Physiol. 14: 783-788.

1967. Aspetti dell' organizzazione negli insetti sociali. 2. La sostanza della traccia nei Formicidae, Natura, Milano, 58: 150-172.

Goetsch, W.

1934. Untersuchungen ueber die Zusammenarbeit im Ameisenstaat, $Z$. Morph. Okol. Tiere, 28 : 319-401.

Romeis, B.

1948. Mikroskopische Technik, Leibniz, München.

WILson, E. O.

1963. The social biology of ants, A. Rev. Ent. 8: 345-368. 

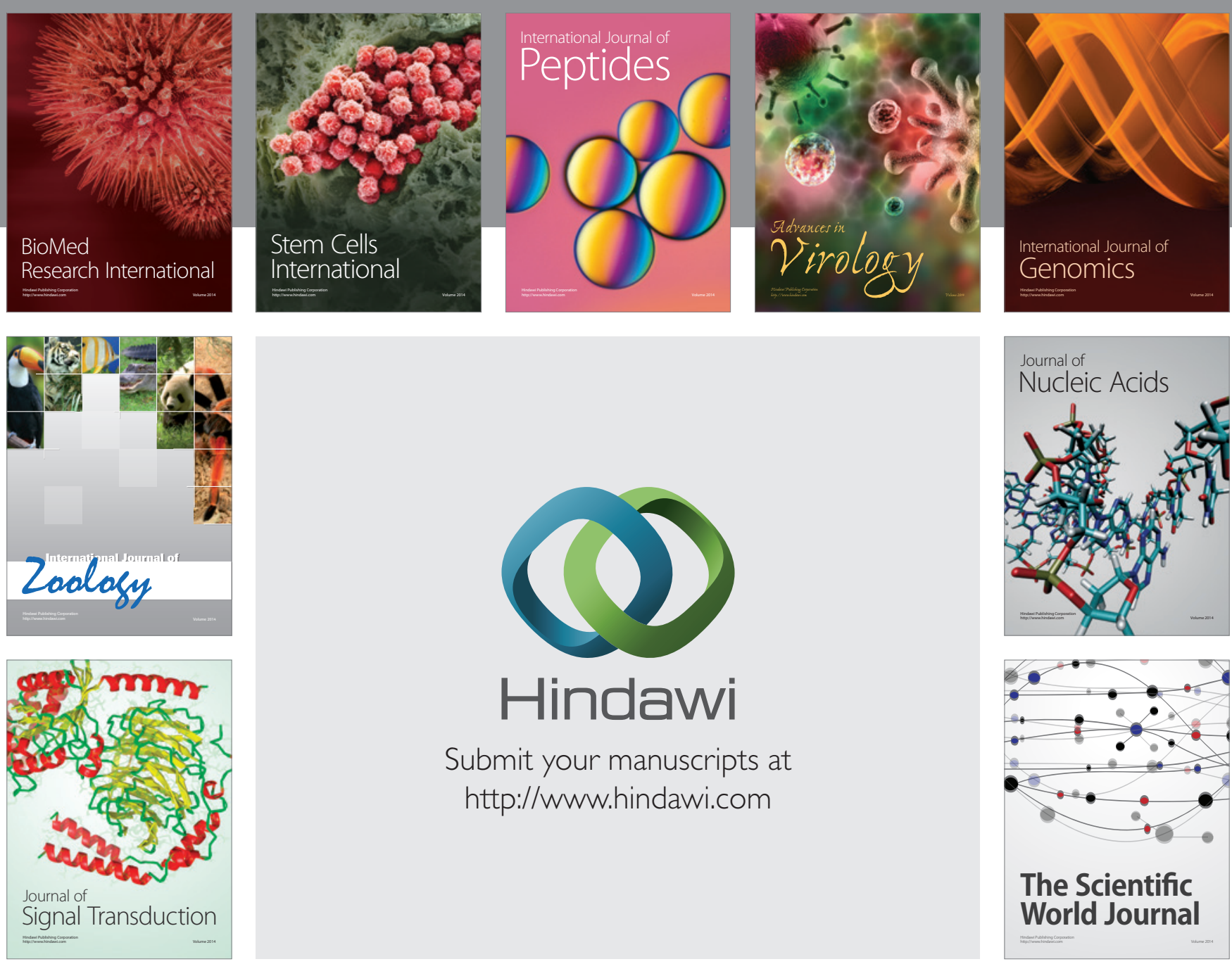

Submit your manuscripts at

http://www.hindawi.com
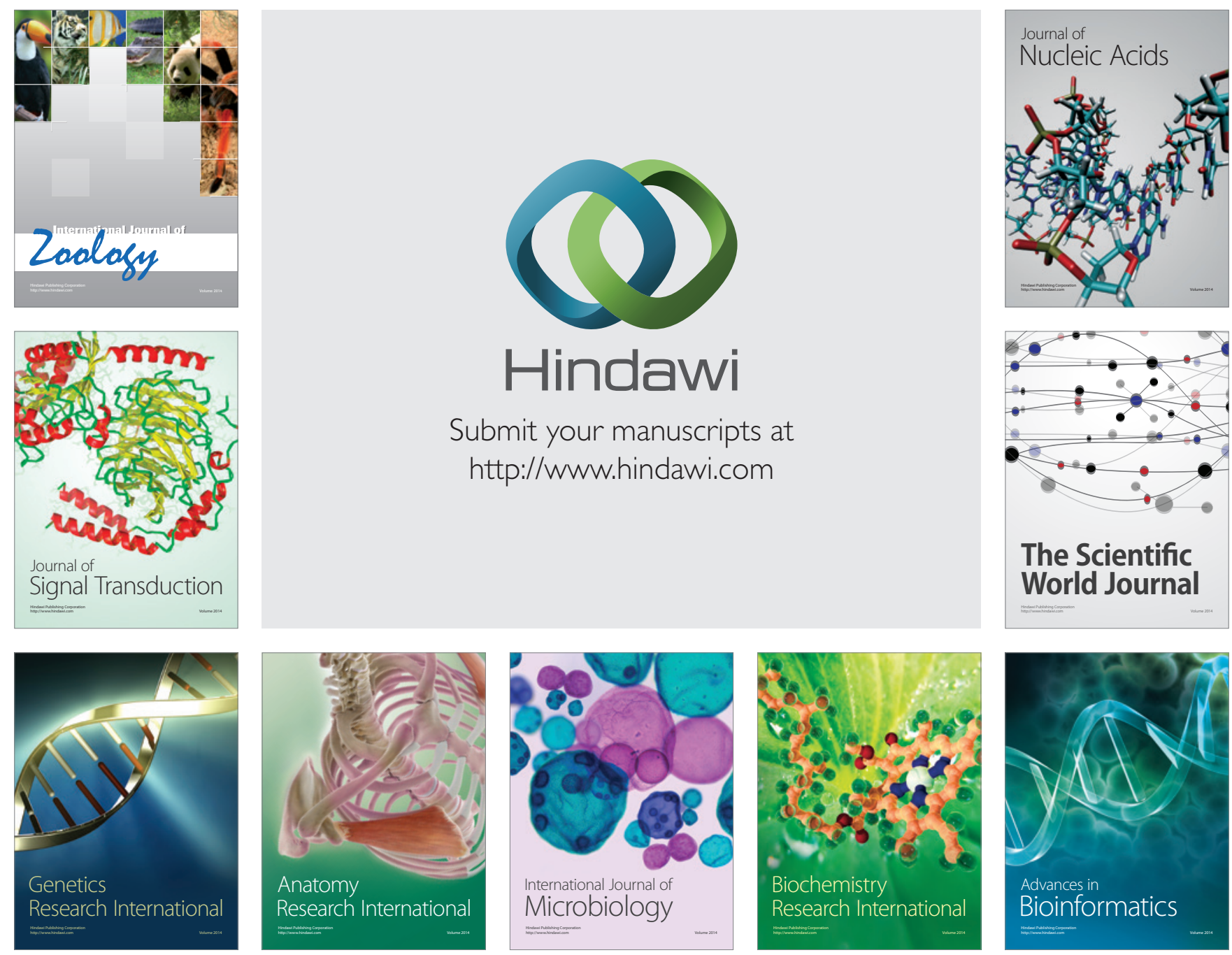

The Scientific World Journal
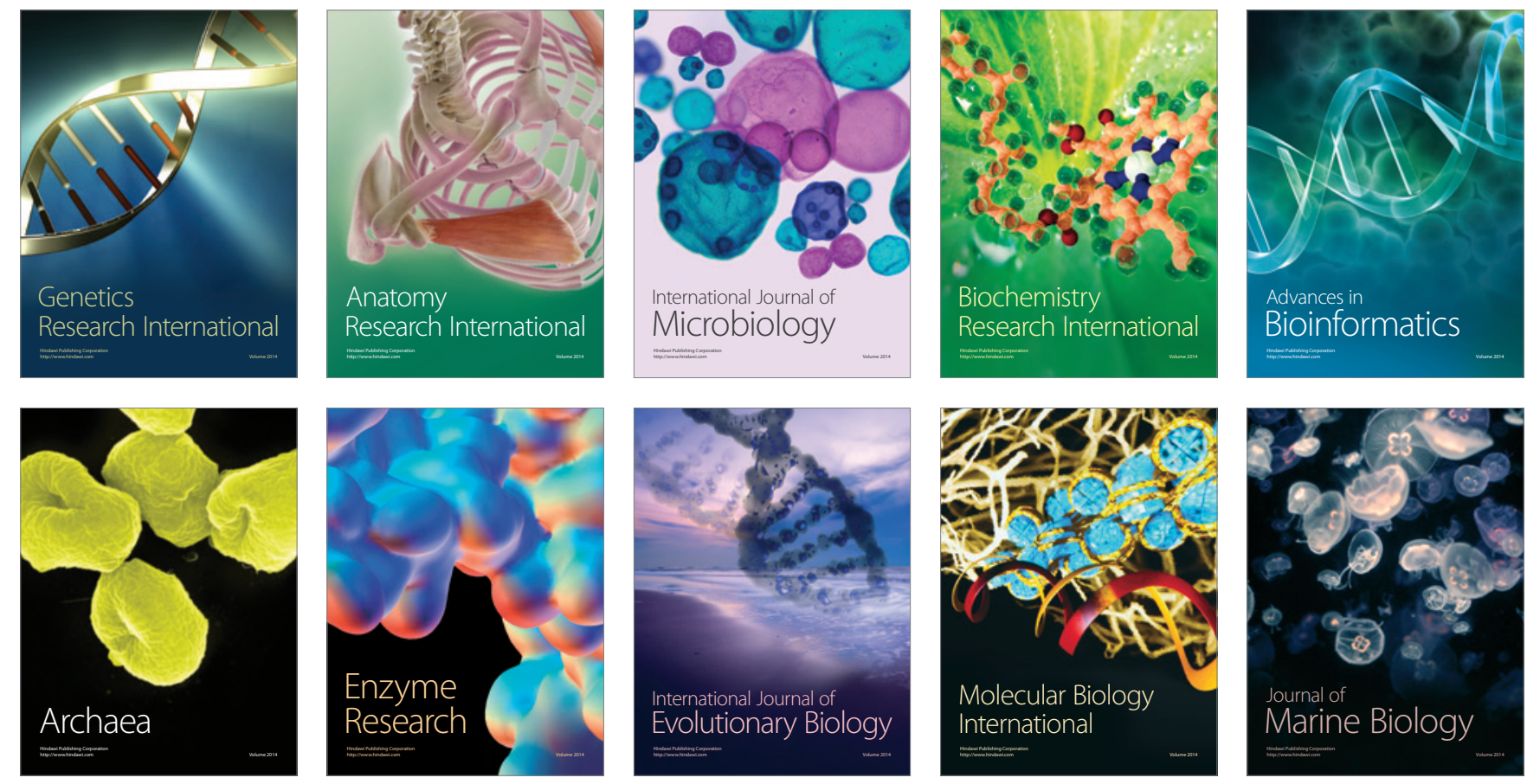